\title{
CDISC CDASH ECG Original Units Terminology
}

National Cancer Institute

\section{Source}

National Cancer Institute. CDISC CDASH ECG Original Units Terminology. NCI Thesaurus. Code $C 78422$

A terminology subset of the CDISC Study Data Tabulation Model (SDTM) Unit codelist created for Clinical Data Acquisition Standards Harmonization (CDASH) ECG Orig inal Units terminology. 